\title{
The Effects of Xylitol on Body Weight Loss Management and Lipid Profile on Diet-Induced Obesity Mice
}

\author{
Nor Ezleen Qistina Ahmad, Noornabeela Md Yusoff \\ Institute of Medical Science Technology, Universiti Kuala Lumpur, Kajang, Selangor \\ Email: ezleen@unikl.edu.my
}

Received 31 July 2015; accepted 9 October 2015; published 12 October 2015

Copyright (C) 2015 by authors and Scientific Research Publishing Inc.

This work is licensed under the Creative Commons Attribution International License (CC BY). http://creativecommons.org/licenses/by/4.0/

(c) $\underset{\mathrm{EY}}{0}$ Open Access

\begin{abstract}
Xylitol is an alternative sweetener which has been previously reported to have many beneficial effects such as prevention from dental caries, reduction of visceral fat and increased synthesis of collagen. However, its role in body weight loss management has not been uncovered before. This study sought to investigate the effects of xylitol on body weight loss management, blood glucose and lipid profile on diet-induced obesity (DOI) mice. Fifteen male mice were subjected to high fat diet (60 kcal\%) and normal drinking water for 28 days and then randomly divided into three (control, glucose and xylitol) groups. Each group of mice was then fed with normal diet for another 28 days with supplied normal drinking water (control); glucose solution $10 \%$ and xylitol solution $10 \%$. Body weight loss was found to be significantly high in xylitol mice $(2.56 \pm 0.21, p=0.003)$ compared to the other two groups. Lowest blood glucose level was found in the control group mice with the mean $7.65 \pm 0.10(p=0.001)$. Xylitol mice had also showed the lowest total cholesterol level $(4.20 \pm 0.90, p=0.000)$ than the other groups, but highest in HDL level $(2.72 \pm 0.14, p=$ 0.000). In conclusion, these findings proved that xylitol has the potential to reduce body weight, lowering the blood glucose but yet increase the HDL level.
\end{abstract}

\section{Keywords}

Xylitol, Weight Loss, Blood Glucose, Lipid Profile, Diet-Induced Obesity Mice

\section{Introduction}

During the last decade, obesity has become a growing global health problem. With increasingly cheap, high

How to cite this paper: Ahmad, N.E.Q. and Md Yusoff, N. (2015) The Effects of Xylitol on Body Weight Loss Management and Lipid Profile on Diet-Induced Obesity Mice. Journal of Biosciences and Medicines, 3, 54-58.

http://dx.doi.org/10.4236/jbm.2015.310007 
calorie food such as fast food, prepared foods that are high in salt, sugar and fat, combined with our increasingly sedentary lifestyle, it is no wonder that the rate of obesity has rapidly increased around the world. The overconsumption of sugar in the standard diet has had devastating effects on people. A corresponding rise in other chronic conditions including cardiovascular disease instead of diabetes has been noted [1].

One of the ways to iron out these problems is by finding a better sweetener as an alternative to sugar. From a health perspective, xylitol, the five-carbon sugar alcohol had previously reported to have many beneficial health effects. 40 grams per day of xylitol intake orally is safe and well tolerated on both humans and rodents. This amount equals to 10 - 12 teaspoons of sugar with no subjective or objective adverse findings. After administration, lesser insulin is released by xylitol compared to glucose. This is a good thing for those who are concerned with their body weight, as well as for the insulin-sensitive individuals. Apart from driving the glucose into the cells, insulin also tells the body to store even slight excess of carbohydrates as fat, rather than to use them as energy [2].

Suppression of visceral fat accumulation had been found in rats given high fat diet supplemented with xylitol. The relative weight of mesenteric fat was reduced by $23.2 \%$. At the same time, it also suppressed the insulinemia and lipidemia by significantly lowers the plasma insulin and triglyceride concentration to $29.3 \%$ and $54.5 \%$ [3]. The long term intake of xylitol has been found to induce the expression of beta oxidation genes which promote the lypolysis in the liver and adinopect in genes in the adipose tissues. The finding exhibited that xylitol is safe to take in a long period of time [3]. This study, however, would like to investigate the effect of xylitol supplied in the drinks towards body weight loss and lipid profile of diet-induced obesity mice.

\section{Methodology}

\subsection{Acclimatization Week}

All 15 C57BL/6J male's mice were kept under standard pathogen-free conditions. The mice were fed with standard diets and normal drinking water with regular 12:12 light-dark cycle for one week. The mice were housed in the same number per cages. The cages and bedding conditions were checked daily and the cages need to be changed more frequently after the mice become obese. The environment nearby the mice cages were controlled, as noise, traffic or other disturbances will affect body weight and cause bias in the diet induced obesity experiments.

\subsection{Mice Randomization, High Fat Diet Feeding and Measurement of Food and Water Intake}

As there is also individual variation even in the inbred strains of the mice, it is important to collect the baseline data of the mice before experiments. The body weight of all mice were weighed by using weight scale and fasting blood glucose level for all mice were measured by using glucometer before the experiment begin. The mice with body weight below $15 \mathrm{~g}$ or over $25 \mathrm{~g}$ at 4 weeks of age were excluded. The baseline fasting blood glucose level of mice ranges from $40-190 \mathrm{mg} / \mathrm{dl}$ at age of 4 weeks but only mice with their fasting blood glucose level between $70-130 \mathrm{mg} / \mathrm{dl}$ were recruited. Mice with ill looking, teeth problem or hair diseases were excluded from the study.

All mice were fed with high fat diets and normal drinking water to become the induced-obesity model. $60 \%$ kcal high-fat diets were given to all mice. The food color was observed daily. Food and water intake of the mice were calculated, measured and recorded daily. Body weight measurement and non-fasting blood glucose level measurement were performed once a week.

\subsection{Standard Diet Feeding with Normal Drinking Water, $10 \%$ Glucose and $10 \%$ Xylitol}

After being obese, all mice were divided into three different groups which were control, glucose and xylitol. Each group was administered with three different water solutions as their source of fluid. The normal drinking water was for control group, $10 \%$ glucose water was for glucose group and $10 \%$ xylitol water was for xylitol group. At this moment, all mice were fed with standard diets. Food and water intake of the mice were calculated, measured and recorded daily. Body weight measurement and non-fasting blood glucose level measurement were performed once a week. 


\subsection{Blood Glucose Measurement from Tail Blood}

As for non-fasting blood glucose level measurement, the blood was taken out from the tails. The tails were pricked as less as possible by using single needle ( $26 \mathrm{~g}$ ). The bloods from the tail were then dropped onto glucose strips inserted in the glucometer and the results were recorded.

\subsection{Serum Lipid Profile Measurement}

As for lipid profile measurement, the whole blood samples were collected by using cardiac puncture protocol. The mouse was placed in the chamber before turning on the gas from the carbon dioxide $\left(\mathrm{CO}_{2}\right)$ tank and euthanasia of the mouse was done. The cardiac was punctured by using single needle from the outside. The whole blood sample obtained from the cardiac was centrifuged and the serum was separated for further analysis. The serum lipid profile measurement was performed by using automated biochemistry analyzer.

\subsection{Data Analysis}

All data were presented as a mean and standard deviation of the mice. Significance of the differences was determined by analysis of variance (ANOVA). The data were analyzed by Statistical Package for the Social Sciences (SPSS) statistical software. The $p$ values were considered significant if $<0.05$.

\subsection{Ethical Consideration}

This study was approved by the Animal Ethical Committee of Universiti Kuala Lumpur-Institute of Medical Science and Technology, Malaysia.

\section{Results}

Figure 1 shows the comparison between DOI mice in control, glucose and xylitol group in body weight loss, food and water intake. Xylitol mice shows the highest body weight loss and daily food intake by mean value of $2.56 \pm 0.21(p=0.003)$ and $5.4 \pm 0.40(p=0.000)$. Glucose mice demonstrates the highest water intake which is $10.18 \pm 0.20$, whereas xylitol mice shows the lowest water intake at $9.72 \pm 0.06(p=0.000)$.

Figure 2 exhibits the effect of xylitol towards total cholesterol, triglycerides, HDL and LDL of DIO mice. The cholesterol level in xylitol mice $(4.20 \pm 0.90)$ has the same mean value with the control mice group (4.20 \pm $0.19)$. The highest total cholesterol was found in the glucose mice $(5 \pm 0.20)$. Xylitol mice also shows the highest HDL $(2.72 \pm 0.14, p=0.000)$, but the lowest for both triglycerides $(1.21 \pm 0.90, p=0.000)$ and LDL $(0.24 \pm$ $0.01, p=0.000)$ compared to other groups.

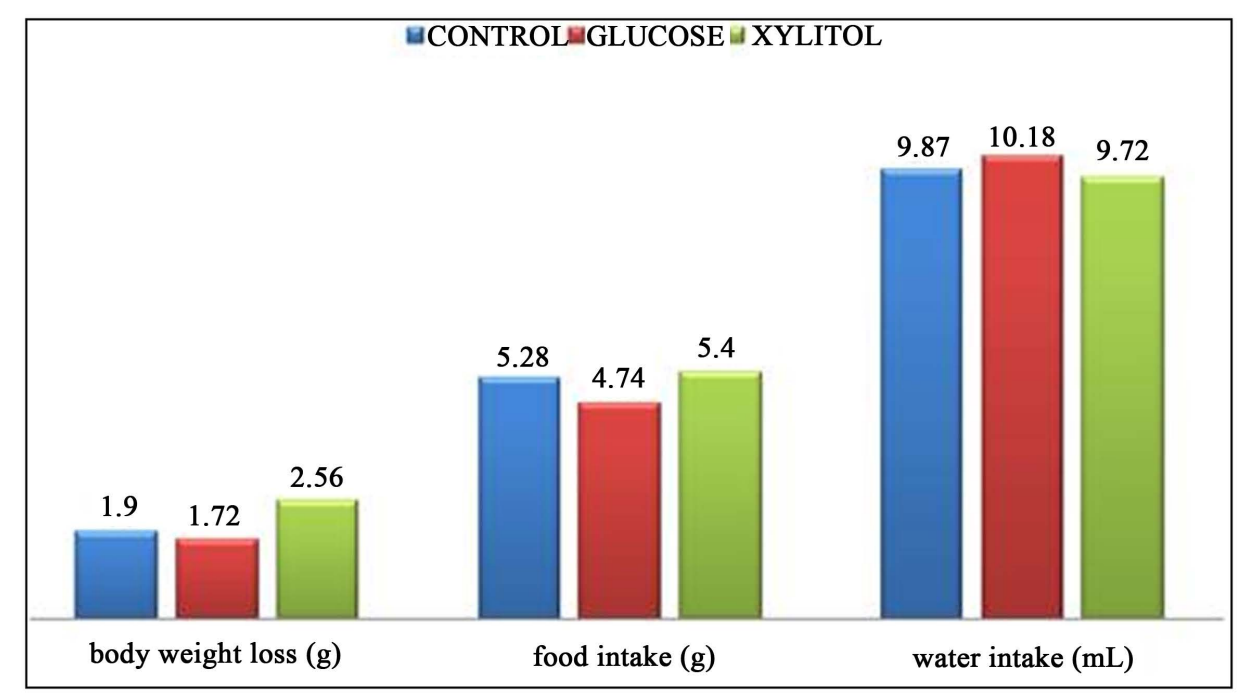

Figure 1. Effects of xylitol on body weight loss management in DOI mice. 


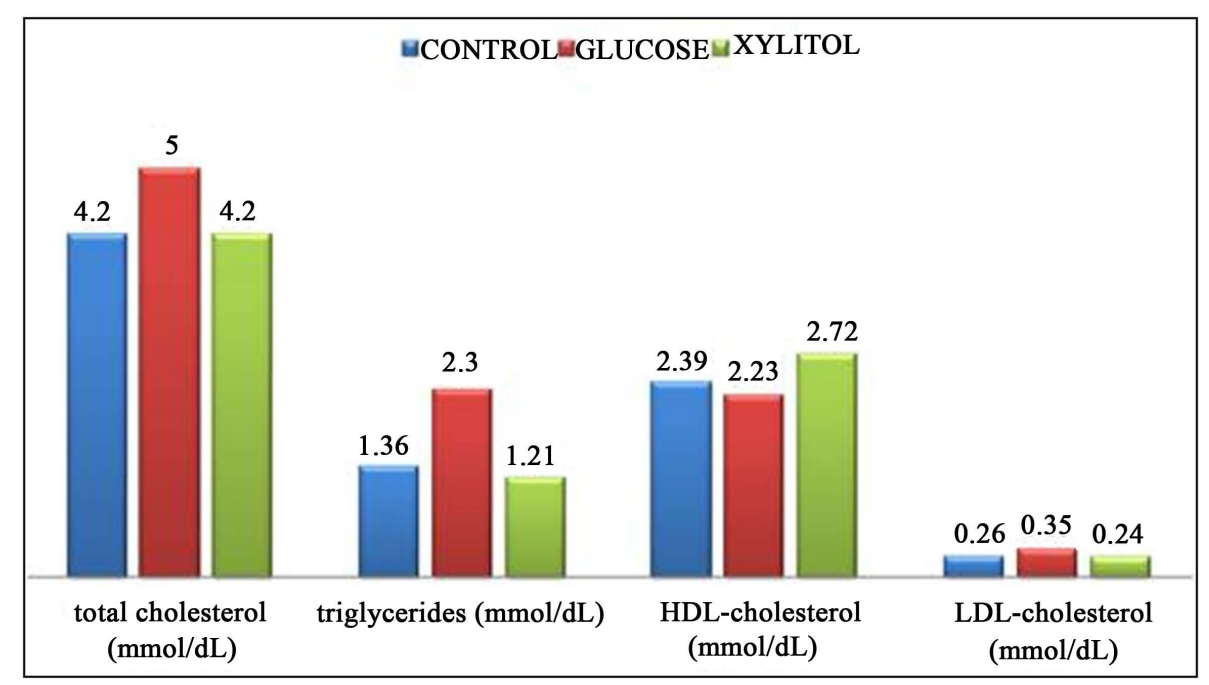

Figure 2. Effects of xylitol on lipid profile in DOI mice.

\section{Discussion}

A successful induction of high-fat diet was observed when body weight gain was found increased to more than $30 \%$ from the initial weight upon arrival of all 15 ICR male mice during high fat diet feeding period. Thus, the body weight gain occurred independently from any increased food and water intake.

Our data shows xylitol mice experienced the highest weight reduction compared to other groups. There are many different factors involved in weight control. One of it is the gastric emptying time. The slower gastric emptying time for the digestion and absorption of nutrients affects the body weight loss. Previous studies have reported that the consumption of xylitol had significantly prolonged the gastric emptying time [4] [5]. It not only prolongs gastric emptying time but also concomitantly accelerates the intestinal transit of nutrients compared to glucose when fed as a single oral dose [6]. The parenteral infusion of glucose substitutes including xylitol has been reported to have several health benefits, such as anti-ketogenic effect, small damaging effect towards vein as well as increased in metabolism [7]. Compared to glucose, xylitol consumption is more rapidly followed by high glycogen storage in the liver [8]. Later this will reduce the generation of glucose from amino acids through gluconeogenesis [9]. Improved nitrogen balanced, augmented level of protein and muscle RNA content were found in critically ill animal infusion by xylitol [10] [11].

This study also demonstrates a significant effect by xylitol towards the level of total cholesterol, triglycerides and LDL. This might be because xylitol supplementation has the ability in suppressing hepatic triglycerides and other cholesterol concentrations of mice induced by high-fat diet. Islam (2011) has reported that xylitol has significant effects in most serum lipids of animal lab. In addition, a recent study by Amo et al. (2011) reported that 8 weeks feeding of xylitol could significantly decrease the serum lipid profile in normal rats fed with a high-fat diet except for HDL-cholesterol, although the food intake data was not presented in their report. Their data showed intake of xylitol induced the expression of lipid degradation and adiponectin genes in the adipose tissues, as well as fatty acids beta oxidation genes, which catabolised the long chain fatty acids in the liver [3]. Tamura et al. (2013) reported that plasma total cholesterol concentration in their xylitol-fed mice is also significantly lower than the control group [12]. They suggested that dietary xylitol has a modest effect towards lipid absorption in mice. It also reported that total serum cholesterol level was significantly lower in xylitol rats compared to the control group [5] [13]. However, no significant differences in serum triglycerides were observed between xylitol and control rats [12].

\section{Conclusion}

From the present finding, the supplementation of xylitol was found to have potential effects against lowering lipid profile measurement of DIO mice, as evidence by biological assessment and chemical analysis finding. The most significant effects were observed in xylitol group which showed improvement and reduction of lipid profile 
measurement. In conclusion, the finding of this experiment and all supportive evidences suggested that xylitol has the potential to reduce body weight, blood sugar and total cholesterol but yet increasing the HDL level.

\section{References}

[1] Bray, G.A., et al. (2002) The Influence of Different Fats and Fatty Acids on Obesity, Insulin Resistance and Inflammation. The Journal of Nutrition, 132, 2488-2491.

[2] Skae, T. (2008) The Harmful Effects of Sugar and Choosing Healthy Alternatives. http://www.naturalnews.com/022692.html

[3] Amo, K., et al. (2011) Effects of Xylitol on Metabolic Parameters and Visceral Fat Accumulation. Journal of Clinical Biochemistry and Nutrition, 49, 1-7. http://dx.doi.org/10.3164/jcbn.10-111

[4] Chukwuma, C.I. and Islam, M.S. (2015) Effects of Xylitol on Carbohydrate Digesting Enzymes Activity, Intestinal glucose Absorption and Muscle Glucose Uptake: A Multi-Mode Study. Food \& Function, 6, 955-962. http://dx.doi.org/10.1039/C4FO00994K

[5] Islam, M.S. (2011) Effects of Xylitol as a Sugar Substitute on Diabetes-Related Parameters in Nondiabetic Rats. Journal of Medicinal Food, 14, 505-511. http://dx.doi.org/10.1089/jmf.2010.0015

[6] Salminen, S., Salminen, E., Koivistoinen, P., Bridges, J. and Marks, V. (1989) Gut Microflora Interactions with Xylitol in the Mouse, Rats and Men. Food and Chemical Toxicology, 23, 985-990. http://dx.doi.org/10.1016/0278-6915(85)90248-0

[7] Sestoft, L. (1985) An Evaluation of Biochemical Aspects of Intravenous Fructose, Sorbitol and Xylitol Administration in Man. Acta Anaesthesiologica Scandinavica, 29, 19-29. http://dx.doi.org/10.1111/j.1399-6576.1985.tb02336.x

[8] Foerster, H., Meyer, E. and Ziege, M. (1972) Hepatische Glykogensynthese in Abaengigket von der Blutglucosekozentration Bein Narkotisierten Ratten. Wiener klinische Wochenschrift, 50, 478-480. http://dx.doi.org/10.1007/BF01487605

[9] Hessov, I. (1985) Which Carbohydrates Should We Recommend for Intravenous Nutrition? Acta Anaesthesiologica Scandinavica, 29, 30-31. http://dx.doi.org/10.1111/j.1399-6576.1985.tb02337.x

[10] Drews, D., et al. (1992) Effect of Excess Xylitol on Nitrogen and Glucose Metabolism in the Parenterally Fed Rats. Journal of Parenteral and Enteral Nutrition, 16, 521-524. http://dx.doi.org/10.1177/0148607192016006521

[11] Ardawi, M.S. (1992) Effects of Xylitol and/or Glutamine Supplemented Parenteral Nutrition on Septic Rats. Clinical Science, 82, 419-427. http://dx.doi.org/10.1042/cs0820419

[12] Tamura, M., Hoshi, C. and Hori, S. (2013) Xylitol Affects the Intestinal Microbiota and Metabolism of Daidzein in Adult Male Mice. International Journal of Molecular Sciences, 14, 23993-24007. http://dx.doi.org/10.3390/ijms141223993

[13] Mäkinen, K.K. and Hämäläinen, M.M. (1985) Metabolic Effects in Rats of High Oral Doses of Galactitol, Mannitol and Xylitol. Journal of Nutrition, 115, 890-899. 